\title{
Application of Cyclone Gas Cap Water Washing Device in Ultra Clean Discharge Treatment Technology of Exhaust Gas
}

\author{
Jingling Hu*, Senlin Yang, Lu Zhong, Yingxin Yang, Xiaotu Hu, Xueliang Xue \\ Guangdong J-tech Environmental Technology Co., Ltd, Guangzhou, Guangdong, China
}

\begin{abstract}
Exhaust gas treatment device of coal fired boiler has been upgraded with ultra clean discharge treatment technology, and the new cyclone gas cap washing device is applied in the second half of the desulfurzing tower systm. This new water scrubbing tray system is composed with water sprays, ceramic packing, cyclone gas cap and independent water tank, which is proven by field tests, has exceling effect on exhaust gas treatment, and can decrease concentration of aerosol in exhaust gas to below $5 \mathrm{mg} / \mathrm{Nm}^{3}$ which is lower than the state discharge standard.
\end{abstract}

\section{Introduction}

Particulate matter and sulfur dioxide are the main pollutants in the atmosphere, which impare the environment and health of beings, and the coal is one of the major sources for atmosphere pollution[1]. China is a coal-fired country with coal as a dominant energy source, and the coal takes up $70 \%$ of the production and consumption of the energy. Harmful substances like particulate matter and sulfur dioxide are generated in the process of coal burning[2-3].According to Emission Standards of Atmosphere Pollutants in Thermal Power Plants(GB1322-2011), the concentration of discharged particulate matter in thermal power plants shall be less than $30 \mathrm{mg} / \mathrm{Nm}^{3}$ after July $1^{\text {st }} 2014$, which includes the emission of aerosol. To meet improving high requirements of environmental protection, current desulfurization devices should include the consideration of the new demands and margin caused by possible higher environmental standards in the future. According to Action Plan for Upgrading and Reforming Coal and Power Conservation and Emission Reduction(NO.[2014]2093) isussed by National Development and Reform Commission, Ministry of Environmental Protection and National Energy Administration on September $12^{\text {th }} 2014$, current Coalfired generating units in eastern region should approach or meet the emission limits of compressor turbine units, namely under the $6 \%$ benchmark oxygen content condition, and emission concentrations of particulate matter, sulfur dioxide and nitrogen oxides should be no higher than $10 \mathrm{mg} / \mathrm{m}^{3}, \quad 35 \mathrm{mg} / \mathrm{m}^{3}$ and $\quad 50 \mathrm{mg} / \mathrm{m}^{3}$ respectively, which encourages other regions to observe theses standards.

Ammonia desulfurization technology can remove sulfur dioxide and particulates simultaneously, and has advantages of low cost of absorbents, no secondary pollution and reusable byproduct ammonium sulfate, which leads to broad application in flue gas treatment in thermal power plants. Ammonia desulfurization is a technology that utilizes liquid ammonia or ammonia hydroxide as absorbent, which reacts with sulfur dioxide in flue gas to generate ammonium sulfite, and then generates ammonium sulfate with forced oxidation. Because of the limitation of process conditions, a large amount of fine droplets, namely aerosol, would be inevitably generated during the process of desulfurization, and they are small in size and difficult to be captured so that they can be readily carried out by flue gas and become the major issue of emission by ammonia desulfurization[4]. James etc. [5] have found that $\mathrm{NH}_{4}$ and $\mathrm{SO}_{2}$ can produce particulates of $\mathrm{NH}_{4} \mathrm{HSO}_{3}$ and $\left(\mathrm{NH}_{3}\right)_{2} \mathrm{SO}_{3}$ through gas phase reaction with presence of aqueous vapor . Jingpei Yan etc.[6] studied the influence of operation parameters on aerosol production process in ammonia desulfurization, and found out two pathways of aerosol generation: (1) the main pathway is that $\mathrm{NH}_{3}$ volatilized from absorbent react with $\mathrm{SO}_{2}$ in flue gas to generate aerosols; (2) desulfurization produces aerosols that are evaporated from absorbent in flue gas with high temperature.

Current desulfurization process in thermal power plants is mainly wet scrubbing tower desulfurization technology, which sprays alkaline solution to absorb $\mathrm{SO}_{2}$, and the gas-liquid contact would form droplets with size of $10-60 \mu \mathrm{m}$ in flue gas which contains suspended solid and dissolved salt, as well as water and aerosols dissolved with sulfate, $\mathrm{SO}_{2}, \mathrm{SO}_{3}$, mote etc, which have the diameter of $0.001-10 \mu \mathrm{m}$. These substances would cloud the sky and cause a series problems for surrounding equipments and environment when they are emitted into air and combined with mist. Traditional zigzag shaped defroster can only remove droplets that have larger diameter than $40 \mu \mathrm{m}$ and cannot remove the smaller aerosols[7].

\footnotetext{
* Corresponding author: Hujl@gdj-tech.com
} 
A new vortex plate washing device is introduced in this article, which has advantages like high separation efficiency, low resistance and clog free etc. Vortex plate uses centrifugal force to separate droplets from flue gas, and the force is in inverse proportion to the radius of gyration, and smaller the radius is , larger the centrifugal force would be and better the separation is, thus using vortex-plate defroster with paralleling vortex plate of small radius can improve separation effect[8].

\section{Mechanism and Design of cyclone gas cap water washing device}

\subsection{Mechanism of the washing device}

The washing device with cyclone gas caps is installed above the top of spray layer in the absorption tower to wash the ammonia gas and ammonium sulfate within the flue gas, in order to decrease the emission of aerosols.

The main parts of the washing device are:

(1) Washing spray layers. Process water is used as water source, which is supplied by water tank and water pump, and there are two spray layers.

(2) Gas cap components. Multiple cyclone gas caps are equispaced, and the structure of the gas cap can let flue gas go through the vortex plate from the bottom to be defrosted and the come out from the top of the cap, and the tray collect the water from the spray and recycle it to the water tank, balancing the water cycle. The gas caps are evenly distributed, well arranged which allow flue gas to pass through well-distributed gas caps with no bias current. The tray is reasonably designed, which can meet operation requirements for boilers. Gas cap components can prevent entrainment from the spraying absorbent in the lower desulfurizing tower. Few remaining aerosols will be significantly decreased after washed twice, which can meet the requirements of ultralow emission.

\section{2 design drawing}

The technical process of the washing device is as shown in Fig. 1, and the structure of cyclone gas cap is as shown in Fig. 2.

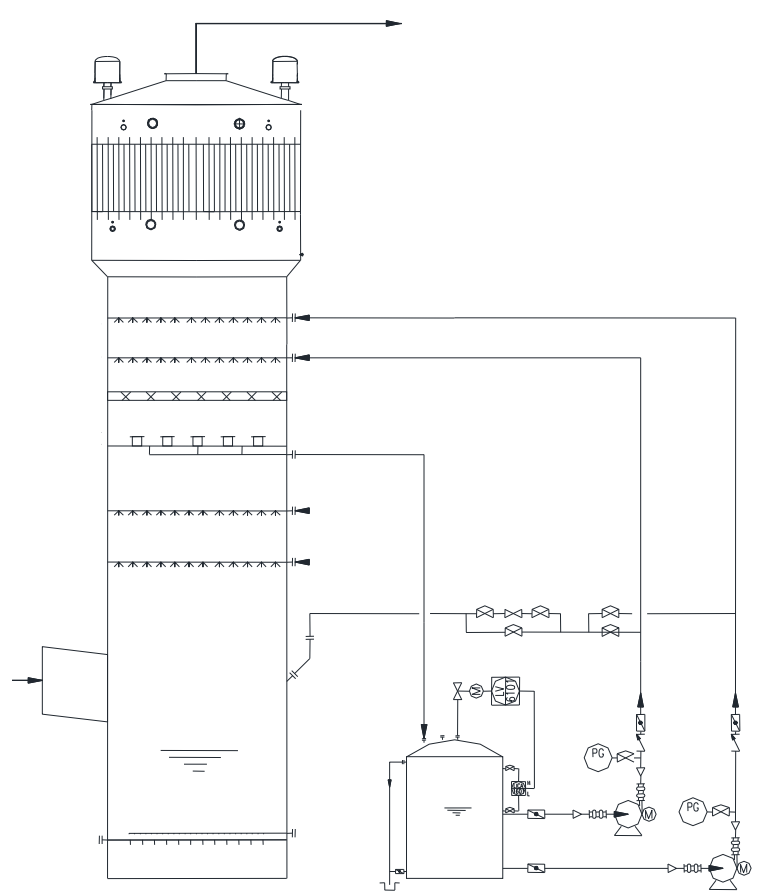

Fig. 1. Flow chart of the washing device system

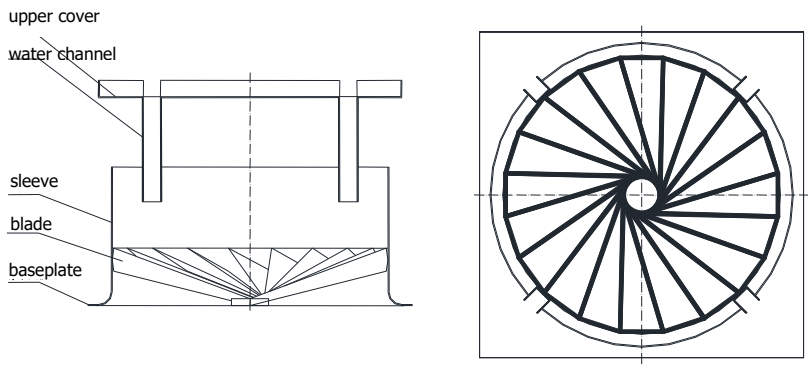

Fig .2. Sketch view of cyclone gas cap

\section{Sample of engineering application}

In order to meet the increasing environmental requirements, flue gas treatment for $1 \#$ boiler in Baling Petrochemical Corp Power Division adopted J-TECH ammonia desulfurization technology to reconstruct the treatment device for ultra clean emission, aiming at the problem of aerosol emission, which implemented the technical proposal of cyclone gas cap water washing device. The main design parameters of washing tray is as follows:

Table 1. The main design parameters of washing tray

\begin{tabular}{lll}
\hline No. & Item & Parameter \\
\hline 1 & Flue gas volume & $270000 \mathrm{Nm}^{3} / \mathrm{h}$ \\
2 & Flue gasTemperature: & $50{ }^{\circ} \mathrm{C}$ \\
3 & Speed of flue gas (inside tower) & $1.86 \mathrm{~m} / \mathrm{s}$ \\
4 & Inner diameter of the tower & $\varphi 7.8 \mathrm{~m}$ \\
5 & Spray amount & $200 \mathrm{~m}^{3} / \mathrm{h} \times 2$ \\
6 & Area ratio of total flow area of & $46 \%$ \\
7 & gas caps & $200 \mathrm{~Pa}$ \\
\hline
\end{tabular}




\section{Results and analysis of the application}

\subsection{Results and analysis of test data}

The measurements of aerosol in flue gas are according to regulations in GB/T16157-1996 Determination of particulates and sampling methods of gaseous pollutants emitted from exhaust gas of stationary source.

Before the reconstruction, a survey was conducted for the conditions of the $1 \#$ boiler in Baling Petrochemical Corp Power Division, and the concentration of its smoke was tested. The smoke concentration is corrected with $6 \%$ oxygen content. The particulate concentration before reconstruction is $28.6 \mathrm{mg} / \mathrm{Nm}^{3}$ (Table 2), which fulfills the requirements of GB 13223-2011 Emission standard of air pollutants for thermal power plants.

Table 2. Emission data of $1 \#$ boiler before reconstruction (unit: $\mathrm{mg} / \mathrm{Nm} 3$ )

\begin{tabular}{|c|c|c|c|c|c|}
\hline $\begin{array}{c}\text { Monitor } \\
\text { ed } \\
\text { pollutant } \\
\mathrm{s}\end{array}$ & $\begin{array}{c}\text { Measured } \\
\text { concentrati } \\
\text { on }\end{array}$ & $\begin{array}{c}\text { Corrected } \\
\text { concentrati } \\
\text { on }\end{array}$ & $\begin{array}{c}\text { Standa } \\
\text { rd }\end{array}$ & $\begin{array}{c}\text { Reach } \\
\text { the } \\
\text { standa } \\
\text { rd or } \\
\text { not }\end{array}$ & $\begin{array}{c}\text { Requireme } \\
\text { nts of ultra } \\
\text { clean } \\
\text { reconstructi } \\
\text { on }\end{array}$ \\
\hline $\begin{array}{c}\text { Particula } \\
\text { te matter }\end{array}$ & 26.57 & 28.6 & 30 & Yes & 10 \\
\hline $\mathrm{SO}_{2}$ & 35 & 38 & 200 & Yes & 35 \\
\hline
\end{tabular}

After the reconstruction, third party authorities tested that, under $100 \%$ load, when the desulfurization device functions in normal working conditions, the average aerosol concentration of original flue gas is $17.2 \mathrm{mg} / \mathrm{Nm}^{3}$ (standard state, dry basis, $6 \% \mathrm{O}_{2}$ ), the average aerosol concentration of cleaned flue gas is $2.6 \mathrm{mg} / \mathrm{Nm}^{3}$ (standard state, dry basis, $6 \% \mathrm{O}_{2}$ ), which completely meets the design requirements.

Table 3. Results of aerosol concentration of original flue gas

\begin{tabular}{|c|c|c|c|c|c|c|c|}
\hline \multirow{2}{*}{$\begin{array}{c}\text { Sample } \\
\text { No. }\end{array}$} & $\begin{array}{c}\text { Volume of } \\
\text { flue gas }\end{array}$ & $\begin{array}{c}\text { Weight } \\
\text { before } \\
\text { sampli } \\
\text { ng }\end{array}$ & \begin{tabular}{|c|} 
Weight \\
after \\
sampling
\end{tabular} & $\begin{array}{l}\text { Weight } \\
\text { of } \\
\text { aerosol }\end{array}$ & $\begin{array}{c}\text { Oxyge } \\
n \\
\text { content }\end{array} \mid$ & $\begin{array}{r}\text { aerosol } \\
\text { concentration } \\
\left(6 \% \mathrm{O}_{2}\right)\end{array}$ & Average \\
\hline & $\begin{array}{c}\mathrm{L}(\text { standard } \\
\text { state, dry } \\
\text { basis })\end{array}$ & $\mathrm{g}$ & g & $\%$ & $\%$ & $\mathrm{mg} / \mathrm{m}^{3}$ & $\mathrm{mg} / \mathrm{m}^{3}$ \\
\hline$\# 1$ & 611 & $\begin{array}{c}17.706 \\
8 \\
\end{array}$ & 17.7209 & 14.1 & 5.07 & 21.74 & \multirow{5}{*}{17.2} \\
\hline$\# 2$ & 669 & $\begin{array}{c}18.071 \\
2 \\
\end{array}$ & 18.0819 & 10.7 & 5.12 & 15.10 & \\
\hline$\# 3$ & 683 & \begin{tabular}{|c|}
17.828 \\
7 \\
\end{tabular} & 17.8386 & 9.9 & 5.17 & 13.73 & \\
\hline$\# 4$ & 697 & $\begin{array}{c}18.007 \\
0\end{array}$ & 18.0224 & 15.4 & 5.11 & 20.85 & \\
\hline$\# 5$ & 1697 & $\begin{array}{c}17.921 \\
4\end{array}$ & 17.9483 & 26.9 & 4.97 & 14.83 & \\
\hline
\end{tabular}

Table 4. Results of aerosol concentration of cleaned flue gas

\begin{tabular}{c|c|c|c|c|c|c|c}
\hline \multirow{2}{*}{$\begin{array}{c}\text { Sample } \\
\text { No. }\end{array}$} & $\begin{array}{c}\text { Volume of } \\
\text { flue gas }\end{array}$ & $\begin{array}{c}\text { Weight } \\
\text { before } \\
\text { sampling }\end{array}$ & $\begin{array}{c}\text { Weight after } \\
\text { sampling }\end{array}$ & $\begin{array}{c}\text { Weight } \\
\text { of } \\
\text { aerosol }\end{array}$ & $\begin{array}{c}\text { Oxygen } \\
\text { content }\end{array}$ & $\begin{array}{c}\text { aerosol } \\
\text { concentration } \\
\left(6 \% \mathrm{O}_{2}\right)\end{array}$ & Average \\
\cline { 2 - 7 } \\
$\begin{array}{c}\text { state, dry } \\
\text { basis) }\end{array}$ & $\mathrm{g}$ & $\mathrm{g}$ & $\%$ & $\%$ & $\mathrm{mg} / \mathrm{m}^{3}$ & $\mathrm{mg} / \mathrm{m}^{3}$ \\
\hline
\end{tabular}

\begin{tabular}{|c|c|c|c|c|c|c|c|}
\hline$\# 6$ & 772 & 18.1884 & 18.1917 & 3.3 & 5.42 & 4.11 & \multirow{6}{*}{2.6} \\
\hline \#7 & 1201 & 18.5972 & 18.6007 & 3.5 & 5.39 & 2.80 & \\
\hline \#8 & 768 & 18.4378 & 18.4422 & 4.4 & 5.37 & 5.50 & \\
\hline \#9 & 837 & 18.5562 & 18.5574 & 1.2 & 5.31 & 1.37 & \\
\hline \#10 & 847 & 17.8808 & 17.8812 & 0.4 & 5.25 & 0.45 & \\
\hline \#11 & 661 & 18.4720 & 18.4728 & 0.8 & 5.32 & 1.16 & \\
\hline
\end{tabular}

\subsection{Effect comparison of intensity of washing spray}

Under the control of other working conditions, washing sprays are changed to test the effect of water washing tray controlling aerosol emission in the whole system. The effect of washing spray to aerosol concentration is shown in Table 5, judging from the contrast tests (Fig. 3), washing tras have significant controlling effect on ultimate aerosol emission, since when washing sprays are off, the concentration of emitted particulate matter can reach as high as $80.78 \mathrm{mg} / \mathrm{Nm}^{3}$. When washing trays are on, the concentration of emitted particulate matter can be sharply decreased to less than $10 \mathrm{mg} / \mathrm{Nm}^{3}$, and when one layer of washing tray is on, the average aerosol concentration is $5.72 \mathrm{mg} / \mathrm{Nm}^{3}$, which leads to the single layer washing efficiency reaching $90 \%$, and when two layers of washing trays are on, the average aerosol concentration is less than $5 \mathrm{mg} / \mathrm{Nm}^{3}$.

Table 5. Test data of effect of washing spray to aerosol emission

\begin{tabular}{|c|c|c|c|}
\hline No. & $\begin{array}{c}\text { Working } \\
\text { condition of } \\
\text { spray }\end{array}$ & $\begin{array}{c}\text { Standard state } \\
\text { flue gas volume } \\
\left(\mathrm{Nm}^{3} / \mathrm{h}\right)\end{array}$ & $\begin{array}{c}\text { Aerosol } \\
\text { concentration } \\
\mathrm{mg} / \mathrm{Nm}^{3}\end{array}$ \\
\hline 1 & Off & 250752 & 80.78 \\
\hline 2 & One layer & 251680 & 7.55 \\
\hline 3 & One layer & 239678 & 4.00 \\
\hline 4 & One layer & 260183 & 5.61 \\
\hline 5 & Two layers & 248227 & 5.33 \\
\hline 6 & Two layers & 244339 & 3.67 \\
\hline 7 & Two layers & 263095 & 5.59 \\
\hline 8 & Two layers & 228702 & 3.75 \\
\hline
\end{tabular}

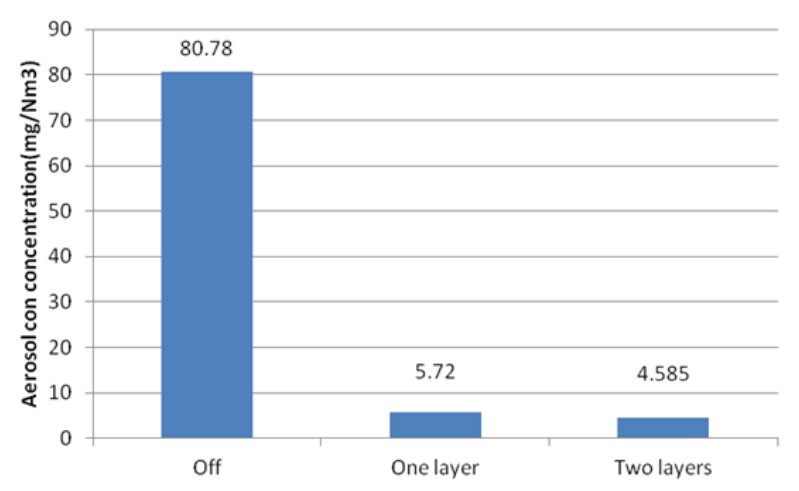

Fig. 3. Comparison of aerosol concentraions under different working conditions after reconstruction 


\section{Conclusion}

From the analyses above, reconstructed water washing tray system of desulfurization and dedusting system of coal fired boiler can significantly reduce emitted aerosol concentration, and the emitted aerosol concentration can be decreased to lower than $5 \mathrm{mg} / \mathrm{Nm}^{3}$ after ultra clean treatment, which is lower than the state standards. It is proved by tests that the water washing tray system can run steadily and reach design requirements. This cyclone gas cap water washing device can help in improving the abatement of aerosols in flue gas and facilitate the control of air pollution nationwide, which is worth publicity in the field of flue gas treatment.

\section{References}

1. J. Zhang, C. Li, C.Zhen, etc. , J.Zhejiang Uni.(Engineering Science). 50, 1516 (2016)

2. X. Ma, Y. Li, S. Zhou,tec., J. Shanghai Un. of Electric Power. 32, 9 (2016)

3. Y. Liang, D. Cheng, Chongqing Electric power Junior College. 21, 51 (2016)

4. J. Yan, L. Yang, X. Shen, Proceedings of the CSEE. 31, 41 (2011)

5. J. L. Vance, L.K. Peters, Industrial and Engineering Chemistry Fundamentals. 15, 202 (1976)

6. J. Yan, L. Yang, J. Bao, etc., Proceedings of the CSEE. 29, 21 (2008)

7. X. Hu, Environmental Engineering. 33, 80 (2015)

8. Z. Wang, Chemical Engineering Design Communications.41, 15 (2015) 